\title{
ANALISA PENENTUAN POSISI HORISONTAL DI LAUT DENGAN MAPSOUNDER DAN AQUAMAP
}

\author{
Khomsin ${ }^{1}$, G Masthry Candhra Separsa \\ ${ }^{1}$ Departemen Teknik Geomatika, FTSLK-ITS, Kampus ITS Sukolilo, Surabaya, 60111, Indonesia \\ e-mail: ${ }^{1}$ khomsin@geodesy.its.ac.id
}

\begin{abstract}
Abstrak
Salah satu komponen dalam survey hidrografi ataupun survey bathimetri di laut adalah pengukuran posisi horisontal. Perkembangan teknologi Global Navigation Satellite System (GNSS), khususnya Global Positioning System (GPS) yang sangat pesat, sangat membantu dalam hal penentuan posisi horisontal di laut. Ada beberapa variasi metode dan teknik pengukuran dengan GPS untuk menentukan posisi di laut yaitu absolut dan diferensial (kinematic, real time kinematic dan real time DGPS). Saat ini banyak surveyor yang melakukan penentuan posisi dengan menggunakan GPS Navigasi yaitu Mapsounder dan Aquamap dengan alasan mudah dan murah. Penelitian ini bertujuan untuk menganalisa ketelitian posisi horisontal di laut dengan menggunakan fish finder (Mapsounder dan Aquamap). Tingkat ketelitian posisi horisontal dapat diketahui dengan cara membandingkan posisi horisontal yang diperoleh dari GPS Internal fish finder dengan GPS Geodetik. Penghitungan nilai standar deviasi dilakukan untuk mengetahui nilai ketelitian posisi horisontal fish finder. Dimana hasil penelitian ini menunjukkan bahwa ketelitian posisi horisontal menggunakan Aquamap terhadap GPS Geodetik yang terikat dengan CORS adalah sebesar $\pm 1,474 \mathrm{~m}$. Sedangkan ketelitian Mapsounder terhadap GPS Geodetik yang terikat dengan CORS adalah sebesar $\pm 2,537 \mathrm{~m}$. Mengacu kepada IHO dan SNI, tingkat keakuratan data posisi horisontal Aquamap dan Mapsounder berada pada orde 1 (diatas 95\%), yakni 100\% untuk Aquamap dan 97,7\% untuk Mapsounder.
\end{abstract}

Kata Kunci : GPS, Mapsounder, Aquamap, survey hidrografi

\begin{abstract}
One component in hydrographic survey or bathymetry survey at sea is horizontal positioning. The development of GNSS technology, especially the very fast of GPS, is very helpful in sea horizontal positioning. There are several variations of GPS measurement methods and techniques for determining horizontal position at sea: absolute and differential (kinematic, real time kinematic and real time DGPS). Because of very easy and cheap, currently many hydrographic surveyors use GPS Navigation to determine horizontal positioning at sea such as Mapsounder and Aquamap. Therefore, this study aims to analyze the accuracy of horizontal positioning at sea using fish finder (Mapsounder and Aquamap). The level of horizontal positioning accuracy can be known by comparing GPS in fish finder (Mapsounder and Aquamap) with GPS Geodetic. This study indicates that the horizontal position accuracy using Aquamap to Geodetic (CORS) is equal to $\pm 1.474 \mathrm{~m}$ and Mapsounder is equal to $\pm 2,537 \mathrm{~m}$. Referring to IHO and SNI, the accuracy level of Aquamap and Mapsounder horizontal position data is in order 1 (above 95\%) that is 100\% for Aquamap and 97,7\% for Mapsounder.
\end{abstract}

Keywords : GPS, map sounder, aquamap, hydrographic survey

\section{PENDAHULUAN}

Negara Indonesia adalah sebuah negara kepulauan dengan segala kekayaan sumber daya alam dan sumber daya lainnya sebagai anugerah Tuhan Yang Maha Esa yang harus dikelola dengan baik dan penuh rasa tanggung jawab untuk menjadi sumber kemakmuran bagi seluruh rakyat Indonesia. Dalam Undang Undang No 4 Tahun 2011 tentang Informasi Geospasial menyebutkan bahwa dengan ketersediaan informasi geospasial yang lengkap, akurat dan mutakhir, maka masyarakat dan negara dapat melakukan pengelolaan terhadap sumber daya alam dengan basis data. Dalam Undang Undang IG Bab 1 Pasal 1 Ayat 14 disebutkan mengenai peta lingkungan laut nasional, dimana pengertian peta lingkungan laut nasional adalah peta dasar yang memberikan informasi secara khusus untuk wilayah 
laut. Sehingga nantinya pemerintah sebagai penyelenggara dapat menentukan kapan, layak, dan sesuai suatu sumber daya alam dikelola sehingga pada akhirnya kemakmuran sebagai tujuan tata kelola ekonomi negara dapat tercapai (Undang-Undang Republik Indonesia, 2011)

Pemerintahan saat ini ingin mengembalikan kembali jati diri bangsa ini sebagai negara maritim yang kuat. Untuk itu pemerintah ingin membangun tol laut dimana tujuan utamanya adalah mengurangi kesenjangan ekonomi yang terjadi di Pulau Jawa dan Papua misalnya. Konsep tol laut yang akan dibuat pemerintah adalah dengan membangun dan mengembangkan pelabuhan pelabuhan yang tersebar dari Aceh hingga Papua.

Terlebih dahulu pemerintah harus mengetahui data geospasial terkait posisi semua pelabuhan dan juga peta lingkungan laut di wilayah tersebut. Dari posisi pelabuhan nantinya akan dapat ditentukan daerah mana yang pelabuhannya perlu dikembangkan dan daerah mana yang perlu dilakukan pembangunan pelabuhan.

Untuk membangun maupun mengembangkan pelabuhan menjadi pelabuhan berskala besar, maka perlu dilakukan pemetaan lingkungan laut yang sangat detail terkait kondisi topografi dasar laut di daerah pelabuhan. Perlu dilakukan proses survei hidrografi yang nantinya dapat menggambarkan dengan akurat bagaimana kondisi topografi dasar laut suatu daerah pelabuhan (Poerbandono dan Djunarsah, 2005)

Singlebeam Echosounder merupakan alat yang diciptakan untuk melakukan proses pengukuran kedalaman perairan secara akurat (Brouwer, 2008). Namun, mahalnya biaya operasional yang dikeluarkan apabila proses survei hidrografi dilakukan menggunakan alat Echosounder dan perlengkapan pendukung lainnnya membuat pengukuran hidrografi dilakukan dengan menggunakan Mapsounder, karena harganya lebih murah. Banyak pula yang beropini bahwa perbedaan hasil pengukuran kedalaman dengan menggunakan Mapsounder dengan hasil pengukuran kedalaman dengan menggunakan Echosounder hanya berbeda sedikit. Ditambah lagi Mapsounder sudah memiliki GPS internal yang memungkinkan digunakan untuk menentukan posisi horisontal saat proses survei hidrografi berlangsung (Saputra, 2010).

Penentuan posisi horizontal di laut dapat dilakukan dengan menggunakan GPS (Abidin, 2006). Penelitian ini akan mencoba melakukan kajian terhadap perbedaan ketelitian penentuan posisi horisontal Mapsounder yang didapat dari internal GPS Mapsounder dan Aquamap, dengan GPS Geodetik sebagai acuannya. Hasil akhir dari penelitian ini adalah melakukan analisa kelayakan hasil penentuan posisi dengan menggunakan Mapsounder dan Aquamap terhadap Standar Nasional Indonesia dan IHO SP 44 (SNI, 2010; IHO, 2008). Kelayakan yang dimaksud meliputi klasifikasi survei berdasarkan ketelitian hasil penentuan posisi yang parameternya dijelaskan pada SNI survei hidrografi menggunakan Singlebeam Echosounder (kode: 7646:2010) yang dikeluarkan oleh Badan Standardisasi Nasional (BSN) tahun 2010.

\section{METODE}

Lokasi penelitian ini terletak di Selat Madura, Surabaya. Penentuan posisi horisontal di laut dengan menggunakan Mapsounder, Aquamap dan GPS Geodetik Hiper Pro. Mapsounder dan Aquamap merupakan penentuan posisi horisontal dengan GPS Navigasi secara absolut sedangkan GPS Hiper Pro merupakan penentuan posisi secara diferensial yang diikat ke titik CORS ITS Surabaya. Penentuan posisi dengan ketiga alat tersebut dilaksanakan dalam waktu yang bersamaan dengan epok yang sama. Hasil koordinat ketiga data tersebut kemudian dibandingkan satu sama lain dengan mengasumsikan bahwa koordinat hasil GPS Hiper Pro merupakan nilai yang benar. Dengan demikian dapat dihitung akurasi penentuan posisi horisontal di laut dengan menggunakan Mapsounder dan Aquamap terhadap GPS Geodetic Hiper Pro yang diukur secara diferensial yang diikatkan ke titik CORS ITS Surabaya.

\section{HASIL DAN PEMBAHASAN}

Hasil pengukuran posisi horisontal di lapangan berupa koordinat Northing dan Easting. Data GPS Geodetik pada penelitian ini diikatkan dengan CORS ITS. Dengan nilai koordinat CORS ITS untuk 
Northing adalah 9194906,433 m dan untuk Easting adalah 698128,816 m.

Perbedaan hasil pengukuran (kesalahan linear) antara koordinat Mapsounder dan Aquamap dengan GPS Geodetic Hiper Pro ditunjukkan dengan $d_{12}$. Dimana $d_{12}$ merupakan kesalahan jarak antara titik terukur terhadap titik yang dianggap benar pada waktu pengamatan yang sama. Dalam penelitian ini, titik yang dianggap benar adalah titik yang diperoleh dari hasil pengukuran dengan menggunakan GPS Geodetik Hiper Pro. Penghitungan kesalahan jarak (linear) antar dua koordinat dapat diperoleh dengan menggunakan persamaan berikut:

$$
d_{12}=V\left(\left(E_{u}-E_{t}\right)^{2}+\left(N_{u}-N_{t}\right)^{2}\right)
$$

$$
\begin{aligned}
\text { Keterangan : } \\
\mathrm{d}_{12}=\text { Selisih Jarak antar dua koordinat } \\
\mathrm{E}_{\mathrm{t}}=\text { Easting Geodetik } \\
\mathrm{E}_{\mathrm{u}}=\text { Easting map/aqua } \\
\mathrm{N}_{\mathrm{t}}=\text { Northing Geodetik } \\
\mathrm{N}_{\mathrm{u}}=\text { Northing map/aqua }
\end{aligned}
$$

Tabel 1 dan Tabel 2 adalah tabel yang menyajikan data posisi horisontal data hasil pengukuran menggunakan GPS Geodetik- Mapsounder dan GPS Geodetik - Aquamap yang telah diikatkan dengan CORS. Pada penelitian ini terdapat 300 data yang diuji, dimana data pengukuran tersebut merupakan koordinat Universal Transverse Mercator (UTM) Zona $49 \mathrm{~S}$.

Nilai kesalahan jarak (linear) pada Tabel 1 terbesar pada alat Mapsounder yang ditunjukkan pada

\begin{tabular}{|c|c|c|c|c|c|}
\hline \multirow[b]{2}{*}{ No } & \multicolumn{2}{|c|}{ GEODETIK } & \multicolumn{2}{|c|}{ MAPSOUNDER } & \multirow[b]{2}{*}{$d_{12}(m)$} \\
\hline & $N(m)$ & $E(m)$ & $N(m)$ & $E(m)$ & \\
\hline 1 & 9204647,77 & 696930,392 & 9204648 & 696932 & 1,624 \\
\hline
\end{tabular}
Tabel 1 adalah sebesar 7,341 meter dan nilai kesalahan jarak terkecilnya adalah sebesar 0,021 meter.

Tabel 1. Data Pengukuran Posisi Horisontal Menggunakan GPS Geodetik Terikat CORS dan Mapsounder

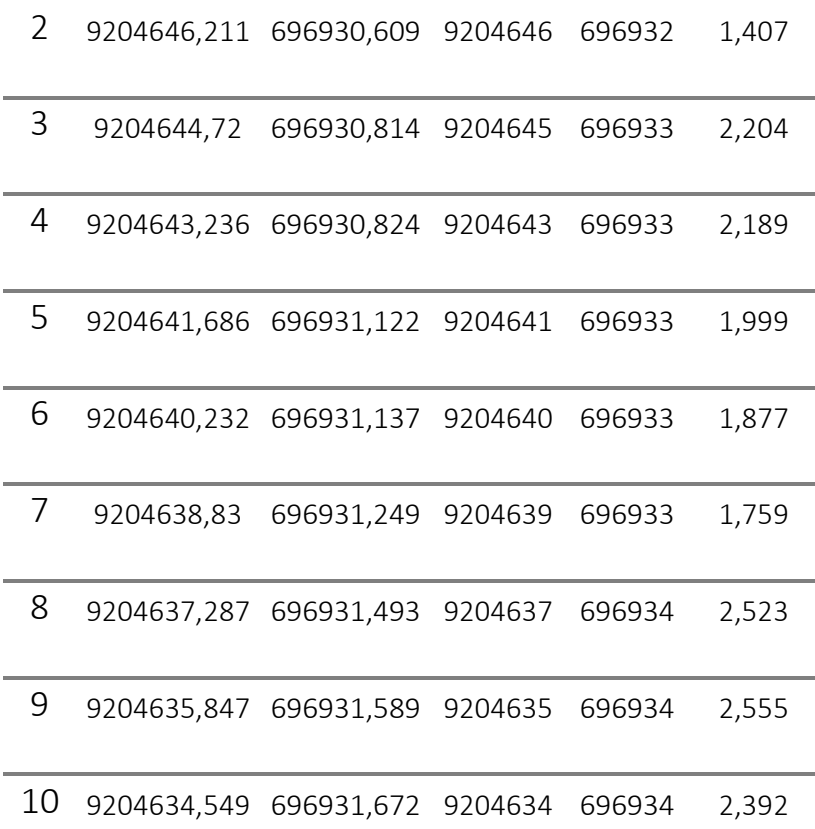

Nilai kesalahan jarak terbesar pada alat Aquamap yang ditunjukkan pada Tabel 2 adalah sebesar 3,073 meter, dan nilai kesalahan jarak terkecilnya adalah sebesar 0,021 meter.

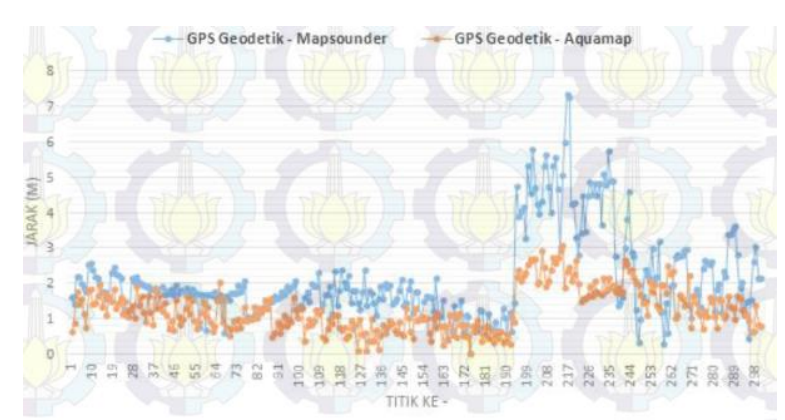

Gambar 1. Grafik kesalahan IInear posisi horisontal Mapsounder vs GPS Geodetik dan Aquamap vs GPS Geodetik

Tabel 2. Data Pengukuran Posisi Horisontal Menggunakan GPS Geodetik Terikat CORS dan Aquamap

GEODETIK

AQUAMAP

\begin{tabular}{lccccc}
\cline { 2 - 5 } & $\mathrm{N}(\mathrm{m})$ & $\mathrm{E}(\mathrm{m})$ & $\mathrm{N}(\mathrm{m})$ & $\mathrm{E}(\mathrm{m})$ & $(\mathrm{m})$ \\
\hline 1 & 9204647,77 & 696930,392 & 9204648 & 696931 & 0,650 \\
\hline 2 & 9204646,211 & 696930,609 & 9204647 & 696931 & 0,881
\end{tabular}




\begin{tabular}{ccccccc}
3 & 9204644,720 & 696930,814 & 9204646 & 696932 & 1,745 \\
\hline 4 & 9204643,236 & 696930,824 & 9204644 & 696932 & 1,402 \\
& & & & & \\
\hline 5 & 9204641,686 & 696931,122 & 9204643 & 696932 & 1,580 \\
\hline 6 & 9204640,232 & 696931,137 & 9204641 & 696932 & 1,155 \\
\hline 7 & 9204638,830 & 696931,249 & 9204639 & 696932 & 0,770 \\
\hline 8 & 9204637,287 & 696931,493 & 9204639 & 696932 & 1,786 \\
\hline 9 & 9204635,847 & 696931,589 & 9204637 & 696933 & 1,822 \\
\hline 10 & 9204634,549 & 696931,672 & 9204635 & 696933 & 1,402 \\
\hline
\end{tabular}

Gambar 1. menunjukkan kesalahan jarak antara Aquamap dan Mapsounder terhadap GPS Geodetik yang terikat dengan CORS. Dimana grafik warna biru merupakan kesalahan jarak Mapsounder, dan grafik warna oranye merupakan kesalahan jarak Aquamap. Pada Gambar 1 terlihat bahwa grafik berwarna biru lebih besar nilainya di bandingkan dengan grafik warna oranye. Hal ini menunjukkan bahwa kesalahan jarak Mapsounder lebih besar dibandingkan dengan kesalahan jarak Aquamap terhadap GPS Geodetik yang terikat dengan CORS.

Analisa ketelitian posisi horisontal dilakukan dengan mencari nilai standar deviasi antara GPS Geodetik yang terikat pada CORS dengan GPS Internal Aquamap dan antara GPS Geodetik yang terikat pada CORS dengan GPS Internal Mapsounder. Nilai standar deviasi data posisi horisontal dapat dilihat pada Tabel 3.

Tabel 3. Nilai Standar Deviasi Data Posisi Horisontal Aquamap Dan Mapsounder

Terhadap GPS Geodetik Yang Terikat Dengan CORS

\begin{tabular}{ccc}
\hline & Aquamap $(\mathrm{m})$ & Mapsounder $(\mathrm{m})$ \\
\hline$\sigma(\mathrm{m})$ & $\pm 1,474$ & $\pm 2,537$ \\
\hline
\end{tabular}

Tabel 3 diatas menunjukkan ketelitian hasil pengukuran posisi horisontal Aquamap dan 4
Mapsounder terhadap GPS Geodetik yang diikatkan dengan CORS. Terlihat bahwa ketelitian penentuan posisi horisontal Aquamap lebih baik daripada Mapsounder. Ketelitian posisi horisontal Aquamap adalah $\pm 1,474$ meter, sedangkan ketelitian posisi horisontal Mapsounder sebesar \pm 2,537 meter. Secara keseluruhan ketelitian posisi horisontal Aquamap lebih baik daripada Mapsounder. Hal ini dapat terjadi karena kualitas GPS Navigasi pada Aquamap lebih baik daripada Mapsounder.

Selanjutnya dilakukan uji tingkat keakuratan data yang mengacu pada IHO SP 44 dan SNI 7646. Uji tingkat keakuratan data digunakan untuk mengetahui orde ketelitian posisi horisontal. Dengan data posisi horisontal yang dianggap benar adalah posisi horizontal dari GPS Geodetik. Sehingga penentuan batas toleransi kesalahan Mapsounder dan Aquamap didasarkan kepada nilai posisi horisontal yang didapat dari GPS Geodetik. Penghitungan tingkat keakuratan data untuk posisi horisontal yang terikat pada CORS untuk tiap orde dapat dilihat pada Tabel 4 dan Tabel 5 di bawah ini.

Tabel 4. Tingkat Keakuratan Data Posisi Horisontal Aquamap Terhadap GPS Geodetik Yang Terikat Dengan CORS

\begin{tabular}{|c|c|c|}
\hline & Orde Khusus & Orde 1 \\
\hline Data yang memenuhi & 251 & 300 \\
\hline $\begin{array}{l}\text { Tingkat keakuratan } \\
\text { data }\end{array}$ & $83,7 \%$ & $100 \%$ \\
\hline
\end{tabular}

Pada Tabel 4 diatas dijelaskan bahwa dari 300 data penelitian hasil penentuan posisi horisontal menggunakan Aquamap terhadap GPS Geodetik yang terikat dengan CORS, terdapat 251 data yang masuk dalam orde ketelitian khusus, yakni sebesar $83,7 \%$. Dan terdapat 300 data yang masuk dalam orde ketelitian 1, yakni sebesar $100 \%$.

Tabel 5. Tingkat Keakuratan Data Posisi Horisontal Mapsounder Terhadap GPS Geodetik Yang Terikat Dengan CORS

\begin{tabular}{|c|c|c|}
\hline & Orde Khusus & Orde 1 \\
\hline $\begin{array}{l}\text { Data yang } \\
\text { memenuhi }\end{array}$ & 185 & 293 \\
\hline $\begin{array}{l}\text { Tingkat keakuratan } \\
\text { data }\end{array}$ & $61,7 \%$ & $97,7 \%$ \\
\hline
\end{tabular}


Pada Tabel 5 diatas dijelaskan bahwa dari 300 data penelitian hasil penentuan posisi horisontal menggunakan Mapsounder terhadap GPS Geodetik yang terikat dengan CORS, terdapat 185 data yang masuk dalam orde ketelitian khusus, yakni sebesar $61,7 \%$. Dan terdapat 293 data yang masuk dalam orde ketelitian 1, yakni sebesar $97,7 \%$.

\section{KESIMPULAN}

1. Ketelitian penentuan posisi horisontal menggunakan Aquamap terhadap GPS Geodetik yang terikat dengan CORS adalah sebesar \pm 1,474 m. Sedangkan ketelitian Mapsounder terhadap GPS Geodetik yang terikat dengan CORS adalah sebesar $\pm 2,537 \mathrm{~m}$.

2. Tingkat keakuratan data posisi horisontal Aquamap dan Mapsounder yang mengacu pada IHO SP 44 dan SNI 7646 tahun 2010 menjelaskan bahwa Aquamap dan Mapsounder memiliki ketelitian pada orde 1, karena pada orde tersebut tingkat keakuratan Aquamap dan Mapsounder lebih dari 95\%, yakni 100\% untuk Aquamap dan 97,7\% untuk Mapsounder, atau , atau melebihi ketentuan yang ditetapkan oleh IHO SP 44 dan SNI 7646 tahun 2010

\section{DAFTAR PUSTAKA}

Abidin, H. Z., 2006. Penentuan Posisi Dengan GPS Dan Aplikasinya. Jakarta: Pradnya Paramita

Brouwer, P., 2008. Seafloor Classification Using A Single Beam Echosounder. Netherlands: Master Thesis

IHO, 2008. IHO Standards for Hydrographic Surveys. SP 44. International Hydrographic Bureau

Poerbandono, dan Djunarsyah, E., 2005. Survei Hidrografi. Bandung: Refika Aditama

Saputra, F. (2009). Analisa Posisi Planimetris GPS Navigasi Terhadap SP - 44 IHO Pada Survei Batimetri. Surabaya: ITS

SNI, 2010. SNI 7646: Survey Hidrografi Menggunakan Singgle Beam Ecosounder. Jakarta: Badan Standarisasi Nasional

Undang-Undang Republik Indonesia, 2011. UU No. 4 Tentang Informasi Geospasial. Lembaran Negara Republik Indonesia Tahun 2011 Nomor 